\title{
Spatial evaluation of appropriate areas to collect runoff using Analytic Hierarchy Process (AHP) and Geographical Information System (GIS) (case study: the catchment "Kasef" in Bardaskan
}

\author{
Nemat Hamidy ${ }^{1}$ Hamid Alipur ${ }^{2} \cdot$ Seyede Negar Hashemi Nasab ${ }^{3} \cdot$ \\ Ahmad Yazdani ${ }^{4} \cdot$ Saeed Shojaei ${ }^{5}$
}

Received: 19 September 2016/Accepted: 27 September 2016/Published online: 4 October 2016

(c) Springer International Publishing Switzerland 2016

\begin{abstract}
Collecting runoff is used to minimize losses and strengthening water reserves (water resources) in the system of catchments. Identifying suitable locations to collect runoff is an important step towards maximizing water availability and optimal utilization of agricultural land in semi-arid areas. Collecting rainwater and runoff is of measures that can be effective in proper utilization of water available in arid areas. Using traditional Knowledge, constructional skills, and local resources and due to geographical and climate conditions, water collection systems are expanded as a means of extant water supply in different areas. Nevertheless, regardless of indirect impacts on downstream hydrological and ecological systems, methods of collecting runoff are needed to understand better the environmental and hydrological effects of catchment system. For the purpose of spatial evaluation of suitable areas to collect runoff in the catchment "Kasef" in Bardaskan, runoff values are first calculated using the model of curve number and the maps of land use, hydrologic groups of soil, runoff production potential, the distance from both the
\end{abstract}

Saeed Shojaei

s_shojaei@ut.ac.ir

1 Watershed Management, Tarbiat Modarres University, Noor, Iran

2 Young Researchers Club, Bojnourd Branch, Islamic Azad University, Bojnourd, Iran

3 Young Researchers Club, Ghorveh Branch, Islamic Azad University, Ghorveh, Iran

4 International Carbon Sequestration Project, Khorasan Shomali, Master Watershed Management, Islamic Azad University, Noor, Iran

5 Young Researchers and Elite Club, Zahedan Branch, Islamic Azad University, Zahedan, Iran arable lands and residential area are thereafter prepared in the environment of Arc-GIS 9.3 software. Then, they are weighted using Analytical Hierarchy process (AHP) based on the questionnaire forms and the expert choice 11 software and the relative importance of each of the main criteria and their classes are calculated. So the maps are finally combined in Arc-GIS software to determine the convenient localities of collecting runoff. The results showed that, amongst several criteria, according to expert opinions the criterion of runoff potential has allocated the utmost relative importance to assess susceptible areas for collecting runoff. Also, $2.35 \%$ and 114.68 hectares of the catchment area "Kasf" has a very high potential for runoff production and $12.27 \%$ and 598.11 hectares of this catchment has a high potential and $48.66 \%$ and 2371.62 hectares has a very low potential. It was also noticed that $12.39 \%$ and 603.78 hectares of the catchment area "Kasef" has a very high proportion and $0.41 \%$ and 20.14 hectares has a high proportion and $6.89 \%$ and 335.8 hectares has a very low proportion for the susceptible areas to collect runoff. We can finally say that spatial evaluation and identification of suitable areas to collect runoff is an important and necessary step in applying and developing runoff collecting systems in each system of catchments.

Keywords Runoff - Runoff potential - Spatial evaluation · Analytic hierarchy process (AHP) - Kasef catchment

\section{Introduction}

Iran is located in a region in the world that its average annual rainfall is less than one-third of the global annual rainfall. In addition to the inadequacy of precipitation, its temporal and spatial distribution is also much 
inappropriate. So that in large portion of Iran, much of the rainfall has poured in autumn and winter. And this rainfall level is easily shed to seas, lakes, swamps and deserts through direct evaporation as well as raring rivers and watercourses and will be out of reach (Kordavani 2004). Rainfall levels seem little in arid areas like Bardaskan and transient rain is not sufficient to provide watery needs of human, plants and animals. So to combat the water scarcity, we should further be noted to the conservation and optimal utilization of water through appropriate management. Therefore, collecting rainwater can be useful in improving the problem of water scarcity. Collecting rainwater and runoff is of the measures that can be effective in proper utilization of water available in arid regions (Kordavani 2004). There is a potential source of water within a runoff catchment obtained from rainstorms, which can be used as supplementary to meet the watery necessities if properly managed. Thus, collecting runoff is a right choice for capturing and storing superficial water to consume (de Winnaar et al. 2007). Due to the quick response of slopes to precipitation, flowing runoff and the lack of the depth of soil, a significant amount of water received by the area will be inaccessible in steep and mountainous areas. As a result, the ability to properly manage runoff is of particular importance in these areas (Durga Rao et al. 2005; Mbilinyi et al. 2001). In order to centralize, store and collecting runoff obtained from rainfall, collecting rainwater is generally performed in any way for agricultural and domestic consumptions (Sutherland and Fenn 2000; Rockstro 2000). Regarding urban areas, collecting rainwater can also reduce the amount of water in the city as well as reducing the risk of flooding in the passages. Supplementary irrigation of dry farming agriculture by collecting runoff significantly reduces the risk of un-ripeness of the product and improves the utilization of agricultural water. Implementing runoff collecting systems gives farmers the opportunity to produce diverse products as well as improving food security, diet and family economic status (Biazin et al. 2011). In order to collect runoff, there has been required to determine particular and specific locations depending on the physiographic, environmental, technical, and economic-social conditions (Durga Rao et al. 2005). For the purpose of implementing superficial runoff collecting systems, suitable locations are influenced by factors such as the effects of gravity, the distance of pumps and transfer costs. The abovementioned factors, along with other socio-economic aspects, are of influential factors over selecting optimal locations for the implementation of runoff collection systems (de Winnaar et al. 2007). The localization and identification of appropriate locations for the implementation of this technology is one of the most urgent and most important steps in implementing runoff collecting systems. For this purpose, identifying appropriate locations leads to considerable temporal and spatial savings. Providing a clear framework for collecting, storing, analyzing, displaying and converging spatial and non-spatial Geographical Information System (GIS) provides useful attitude for certain purposes. Analytical Hierarchy Process (AHP) was first proposed by the famous American mathematician named "Thomas L-Satty" who sought to provide an

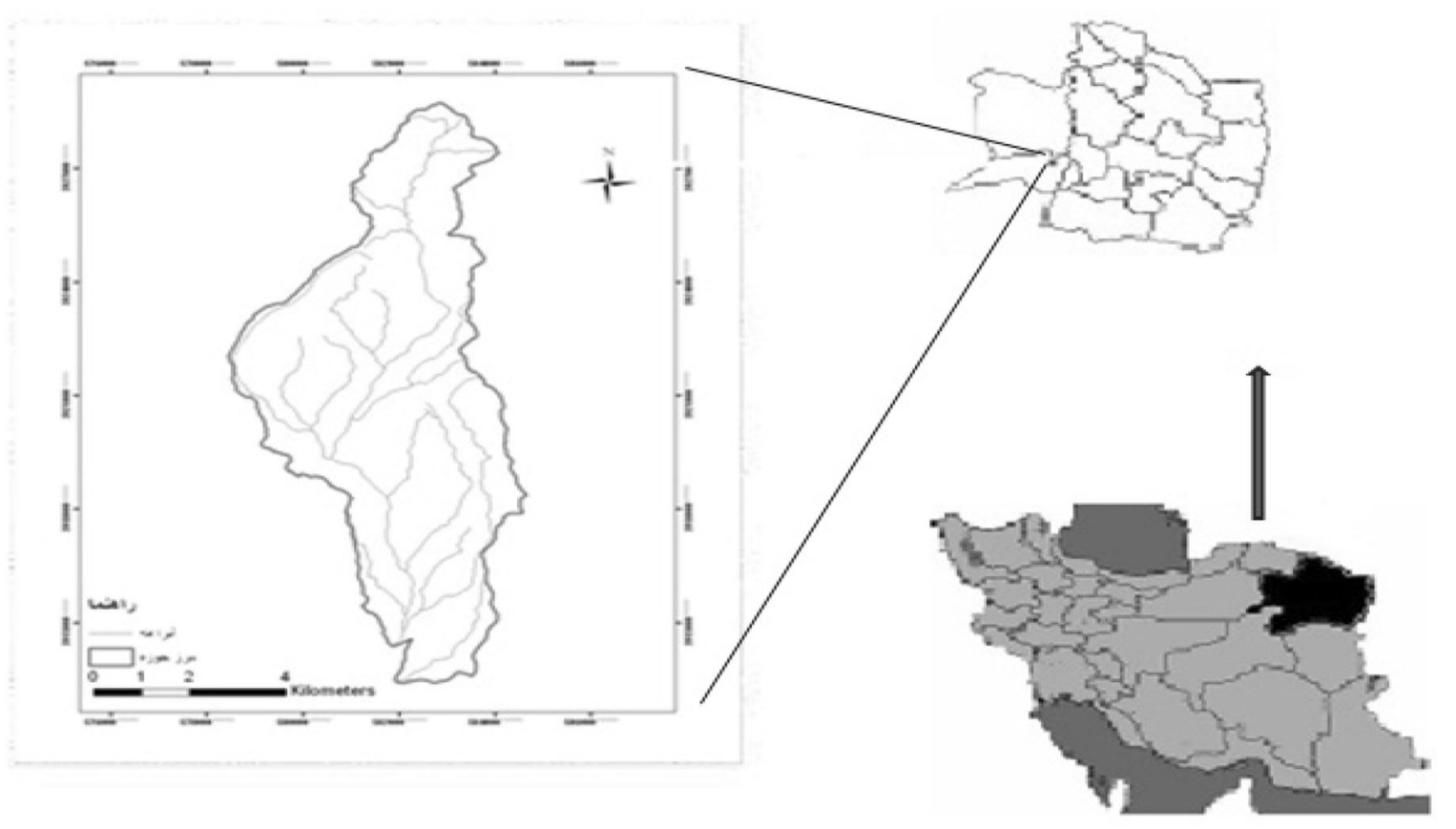

Fig. 1 Geographical position of the catchment "Kasef" 
appropriate strategy for the ordinary people to make decisions about complex issues that several factors were involved in and his findings was known as the "AHP method". In this method, a decision-maker must do a comparison for each pair of criteria involved in the process of decision-making that this analogy was first done descriptively and subsequently quantitatively on the scale of 1-9 and Pair-wise Matrix is finally obtained from the comparison. In group decision-making by AHP, the error of decision will be reduced by others ideas and thoughts and improve and speed things up. Moreover, it is not easy to select decision-makers, and the interference of non-related individuals will create problems in the process of decision-making (Qodsipoor 2006).

We can mention to the following instances about the previous studies: Vorhauer and Hamlett (1996) proposed biophysical criteria, suitability of the soil, slope and land use in the catchment to select runoff collecting level. de Winnaar et al. (2007) have identified locations having the potential of collecting runoff based on capabilities of Geographical Information System (GIS) in the field of Puccini in South Africa. To this end, they have considered spatial variations of the soil, land use, precipitation and slope and also shown that the Geographical Information System (GIS) is also capable of localizing runoff production regions in the catchment and play a major role in this connection through the output including a map of appropriate locations to capture runoff. Mbilinyi et al. (2001) have attempted to identify locations having potential for collecting runoff using the system of decision-making on the basis of Geographical Information System (GIS). Using remotely sensed data, land valuation and GIS, they show the applicability of RS and GIS in identifying susceptible locations for the application of runoff collecting systems. Using Geographical Information System (GIS) and for agricultural use as well as recharging subterranean canals of the catchment "Abkh", Eshghizadeh and his colleagues (1389) identified convenient locations to collect runoff catchment in Gonabad. Nasarian et al. (2015) have examined spatial evaluation of collecting potential of surface water in the catchment system of "Aqh Emam" in Golestan. For determining susceptible fields of collecting rainwater; Maps of precipitation, soil texture, slope and land

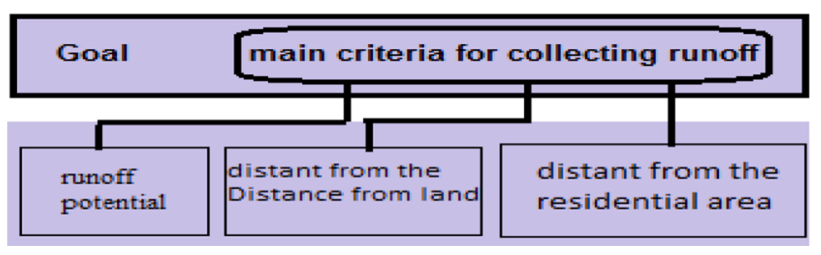

Fig. 2 The decision tree of main criteria for collecting runoff in Analytical Hierarchy Process (AHP)

Table 2 Incompatibility index of random matrices

\begin{tabular}{lllllllllll}
\hline $\mathrm{n}$ & 1 & 2 & 3 & 4 & 5 & 6 & 7 & 8 & 9 & 10 \\
\hline I.I.R & 0 & 0 & 0.58 & 0.9 & 1.12 & 1.24 & 1.32 & 1.41 & 1.45 & $\mathbf{1 . 4 5}$ \\
\hline
\end{tabular}

use were weighted and multiplied on the basis of their importance in determining appropriate fields of collecting runoff. The results showed that the subfields of 3 and 8 have the highest level of proper arenas for collecting rainwater. And the susceptible fields are often corresponded to the pastures for collecting rain in the catchment. The aim of this study is the spatial evaluation of suitable areas to collect runoff using Analytic Hierarchy Process (AHP) and Geographical Information System (GIS) in the catchment "Kasef".

\section{Materials and methods}

The catchment "Kasef", with an area of 48/738 square kilometer, is of central desert catchment located in Bardaskan, of longitude $57^{\circ} 56^{\prime}$ up to $57^{\circ} 52$ and latitude of $35^{\circ} 30^{\prime}$ up to $35^{\circ} 3^{\prime}$. An average gradient of the field is $12 / 32$ percent and the average annual rainfall is $281 \mathrm{~mm}$ that the highest monthly precipitation belongs to the March as $60 / 8 \mathrm{~mm}$, with an average annual temperature of $13 / 8$, the minimum average of annual temperature $7 / 2$, the maximum average of annual temperature 20/4, the annual absolute minimum is $-17 / 0$ in February and the annual absolute maximum is $5 / 39{ }^{\circ} \mathrm{C}$ in July. The prevailing winds are blowing in the east and south-east with the prevailing low speed between 1 and 7 meters per second. And the climate is based on both cold and dry Embreger method and arid
Table 1 Determining the value of criteria toward one another by expertise opinions

\begin{tabular}{ll}
\hline Preferences & Numerical value \\
\hline Perfectly preferred or totally more important or quite more favorable & 9 \\
Very strong preferred or importance or desirability & 7 \\
Strong preferred or importance or desirability & 5 \\
A little preferred or a little more important or slightly better & 3 \\
The same preferred or importance or desirability & 1 \\
Preferences among mentioned distances & $2,4,6$, and 8 \\
\hline
\end{tabular}




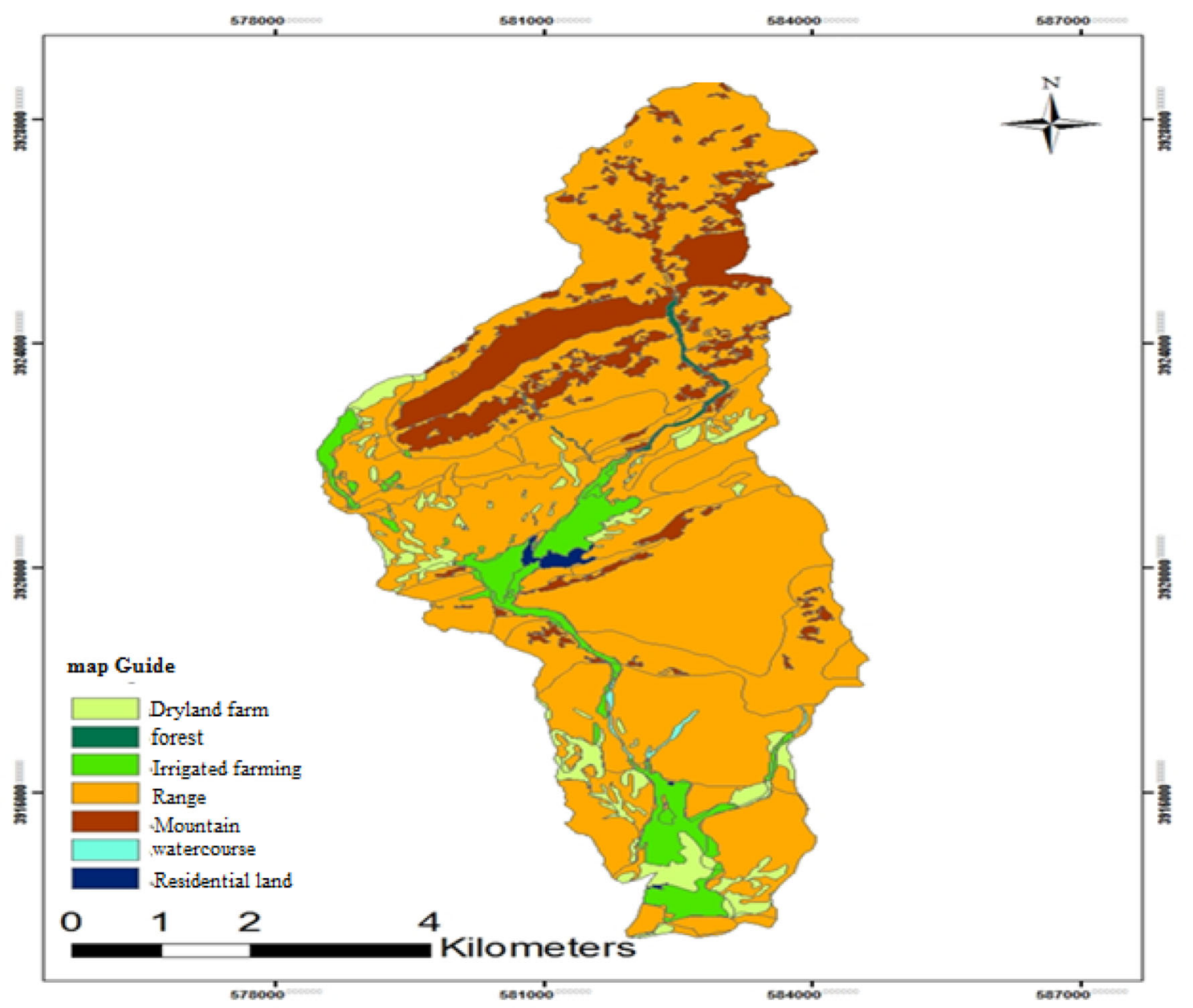

Fig. 3 The map of land use in the catchment "Kasef"

and semi-arid Domarten method. Figure 1 shows geographical location of the catchment "Kasef" in Iran and Bardaskan.

\section{Methods}

For the purpose of spatial evaluation of suitable locations for collecting runoff in the catchment of "Kasef" in Bardaskan, topographic maps of 1: 25,000 was first used to provide the map of the slope. The map of land use was prepared in 7 groups, including rangeland, forest of the riverbank, beds of the watercourse, rocky masses lands, residential area, and dry and irrigated agricultural lands. The soil assessment of the area, examining the depth and texture of the map, and hydrological groups of the soil were prepared. The curve number $(\mathrm{CN})$ was finally prepared by integrating the map of hydrological groups of the soil and land use. Calculation and analysis of runoff was performed using the curve number method $(\mathrm{CN})$. For this purpose, the catchment was divided into cellular networks with dimensions of $1 \times 1 \mathrm{~m}$ and the $\mathrm{CN}$ and runoff was calculated in each cell (DeBarry 2004) so that the CN was first obtained and calculated with the impact of the slope according to the new relation of $\mathrm{CN}$ (1).

$C_{2 s}=$ This means that the $\mathrm{CN}$ was first obtained and estimated based on the slope through the impact of the new relation CN (1) (Neitsch et al. 2005).

$$
\frac{\left(C N_{3}-C N_{2}\right)}{3} \times[1-2 \exp (-13.86 . \mathrm{slp})]+\mathrm{CN}_{2}
$$

$\mathrm{CN} 2 \mathrm{~s}$ is the curve number for former humidity conditions (II) which was moderated by the slope. CN3 is the curve number for former humidity conditions (III), and $\mathrm{CN} 2$ is the curve number for former humidity conditions, SLP (II) is the average gradient of the field to the percentage. 


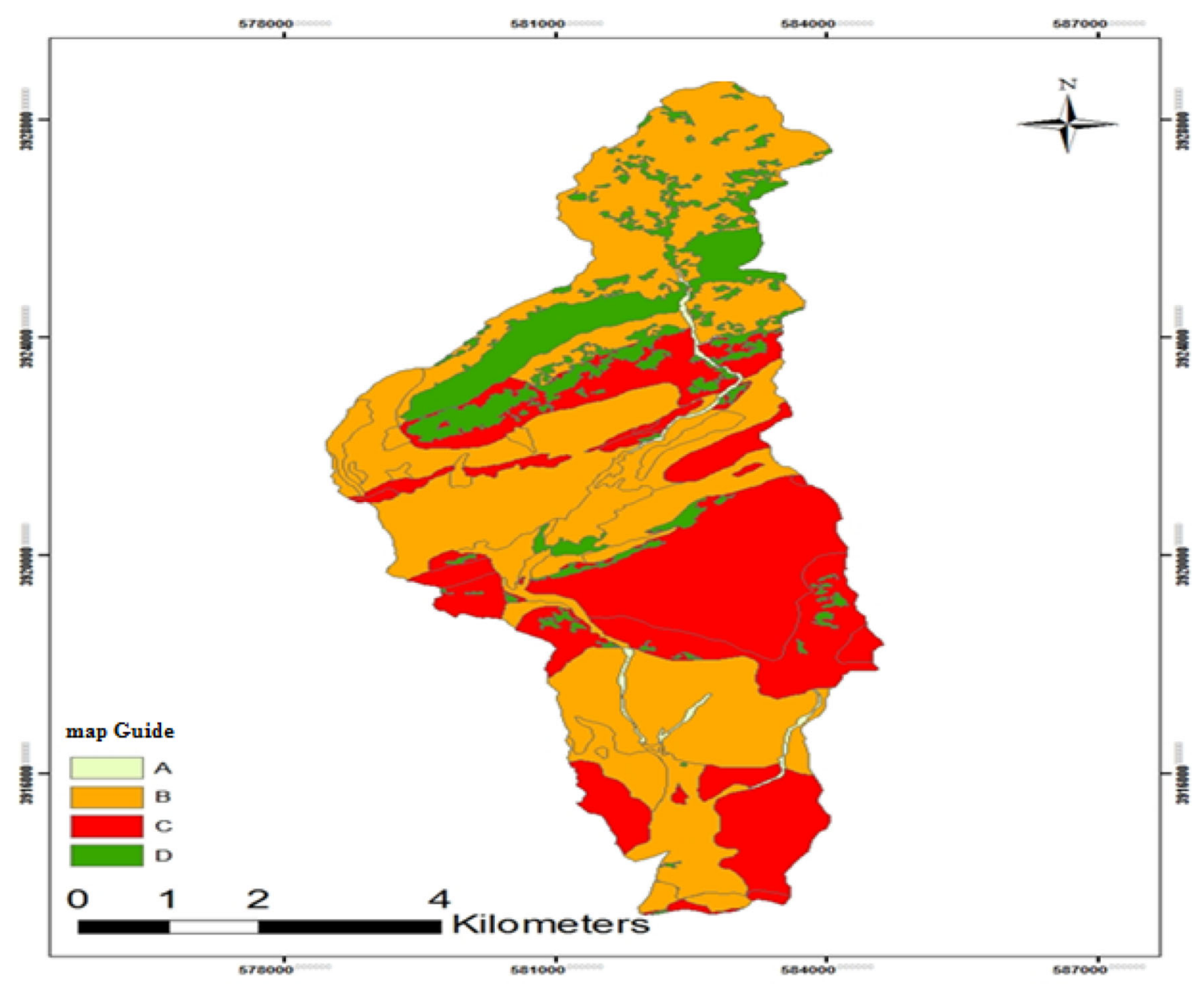

Fig. 4 The map of hydrological groups of soil in the catchment "Kasef"

The mortality rate of the field was calculated in millimeters using the relation (2) and taking into account the 24-h rainfall, the height of the runoff was calculated using the relation (3).

$S=\frac{25400}{C N}-254$

"S" is the mortality rate of the field to the millimeters and " $\mathrm{CN}$ " is the curve number

$Q=\frac{(p-0.2 s)^{2}}{p+0.8 s} p>0.2 s$

"Q" is the height of the runoff to the millimeters, and "P" is the 24-h rainfall, and " $\mathrm{S}$ " is the mortality of the field.

All maps of land use, hydrological groups of soil, potential of producing runoff, distance from the farmland and the distance from the residential area were provided in the software environment of Arc-GIS 9.3. And each of the main criteria maps was classified in five classes. In the AHP method (Analytical Hierarchy Process), due to paired comparison through judging done orally, numerical or even graphical, weights or priorities were mined for criteria involved in decision-making which are in the form of relative numbers (Table 1) (Kheirkhah Zarkesh 2005).

In order to determine the weights of factors affecting the localization, a hierarchical structure should be established for criteria using AHP method (Fig. 2) (Prakash 2003).

Once designing options, paired comparison matrix is formed in return for each criterion, particularly for the options of the issue that are, here, relation classes. The elements of the matrixes are determined using the knowledge of experts. Comparison matrix is entered into the process which resulted in a priority vector of elements. This process is called standardization, in which the relative importance of the classes of criteria is produced. Standardization runs through various methods, but the most popular one is the eigenvector method. Eigenvector method uses the inverse and square matrix decomposition of $\mathrm{D}$ to the eigenvector in exchange for its most Eigen value $(\lambda)$ (relations 4 and 5) (Asgharpoor 2015). 


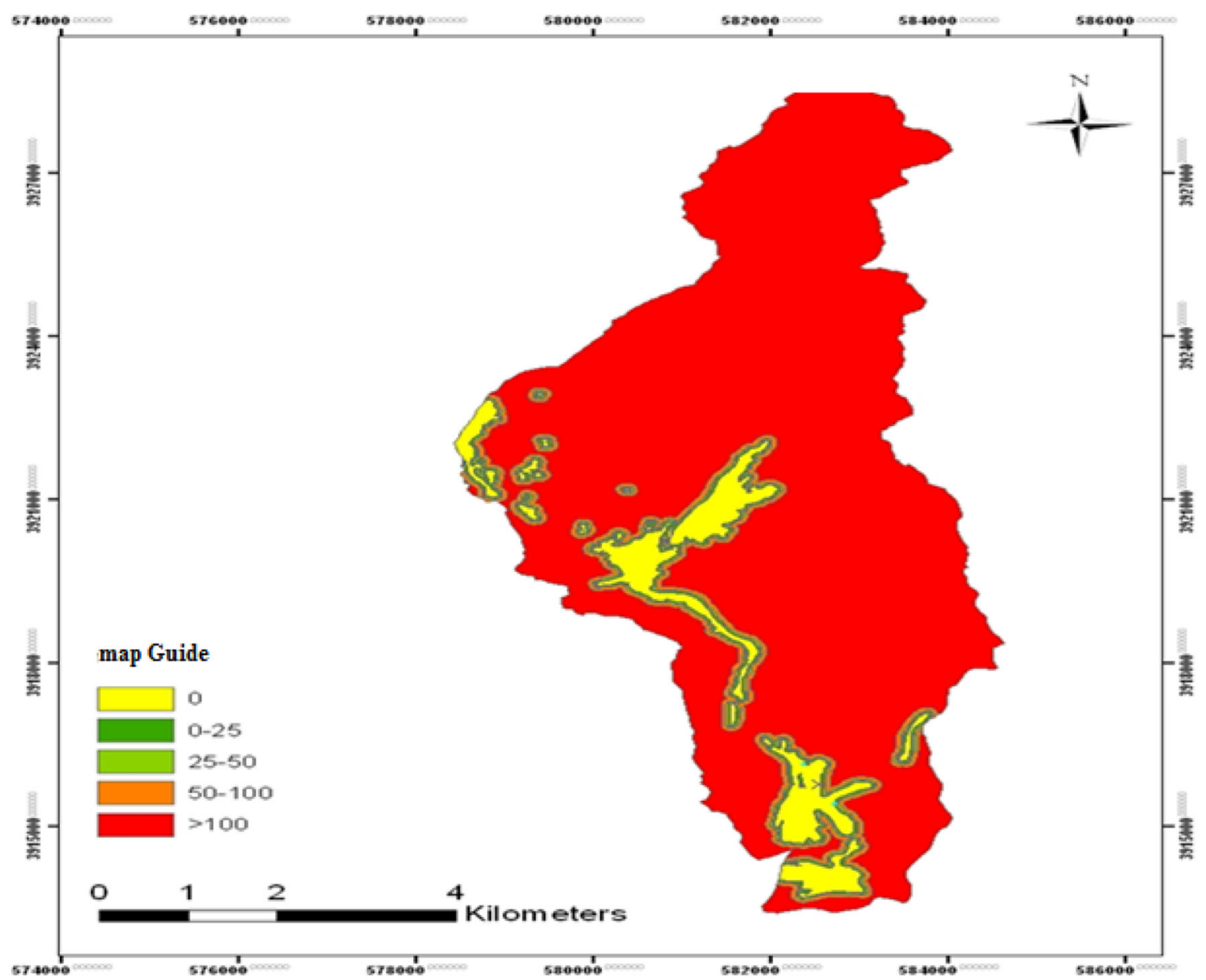

Fig. 5 The map of distance from arable land in the catchment "Kasef"

Namely:

$D \times W=\lambda_{\max } \times W$

and

$w_{\mathrm{i}}=\frac{\sum_{\mathrm{j}=1}^{\mathrm{n}} \mathrm{a}_{\mathrm{ij}} \times \mathrm{w}_{\mathrm{j}}}{\lambda_{\max }}(\mathrm{I}=1,2, \ldots, \mathrm{n})$

where $\mathrm{D}$ is the paired comparison matrix, $\mathrm{W}$ is the vector of the weight and $\lambda$ is a scalar (number). An approximate calculation for the Eigenvector "W" is the use of incremental power $(\mathrm{K})$ for the matrix $\mathrm{D}$ and then normalizing results in the form of relation 6 (Asgharpoor 2015).

$e=[11 \ldots 1]^{T} W=\lim _{k \rightarrow \infty} D^{k} \times e / e^{t} \times D^{k} \times e$

Priority vectors of options are, thereafter, produced in return for all criteria; the calculations are repeated to prioritize and measure the weights of criteria reaching the highest hierarchical level. Monitoring the compatibility of the judgments of decision-makers is based on relevant mathematical relations and investigating the results are on the basis of comparison matrixes. According to the relation
(7), the matrix $A=[a-I j]$ is compatible if the following relation is met among all entries (Qodsipoor 2006):

$a_{i k}=a_{i j} \times a_{j k} \rightarrow i, j, k=1,2,3, \ldots, n$

Given that the paired comparison matrix turns out and priority vector is calculated, these two are imported to the relation (4). The unknown of this relation is the vector of the most Eigen values which can be calculated at this stage. The final Max $\lambda$ is calculated by averaging the abovementioned vector values. On the one hand, $\operatorname{Max} \lambda$ is always greater than or equal to $\mathrm{n}$, and if the matrix was a little bit away from the compatibility mode, Max $\lambda$ will be little distant from $\mathrm{n}$. So the difference between $\operatorname{Max} \lambda$ and $\mathrm{n}$ (namely $\mathrm{n}$ - Max $\lambda$ ) can be a good benchmark for measuring incompatibility matrices. The scale of $(n-\max \lambda)$ is certainly dependent on the value of $n$ (length of the matrix). To alleviate this dependency, the scale can be defined as follows which to be called as an inconsistency index (I.I) (Relation 8):

$I . I=\frac{\lambda_{\max }-n}{n-1}$ 


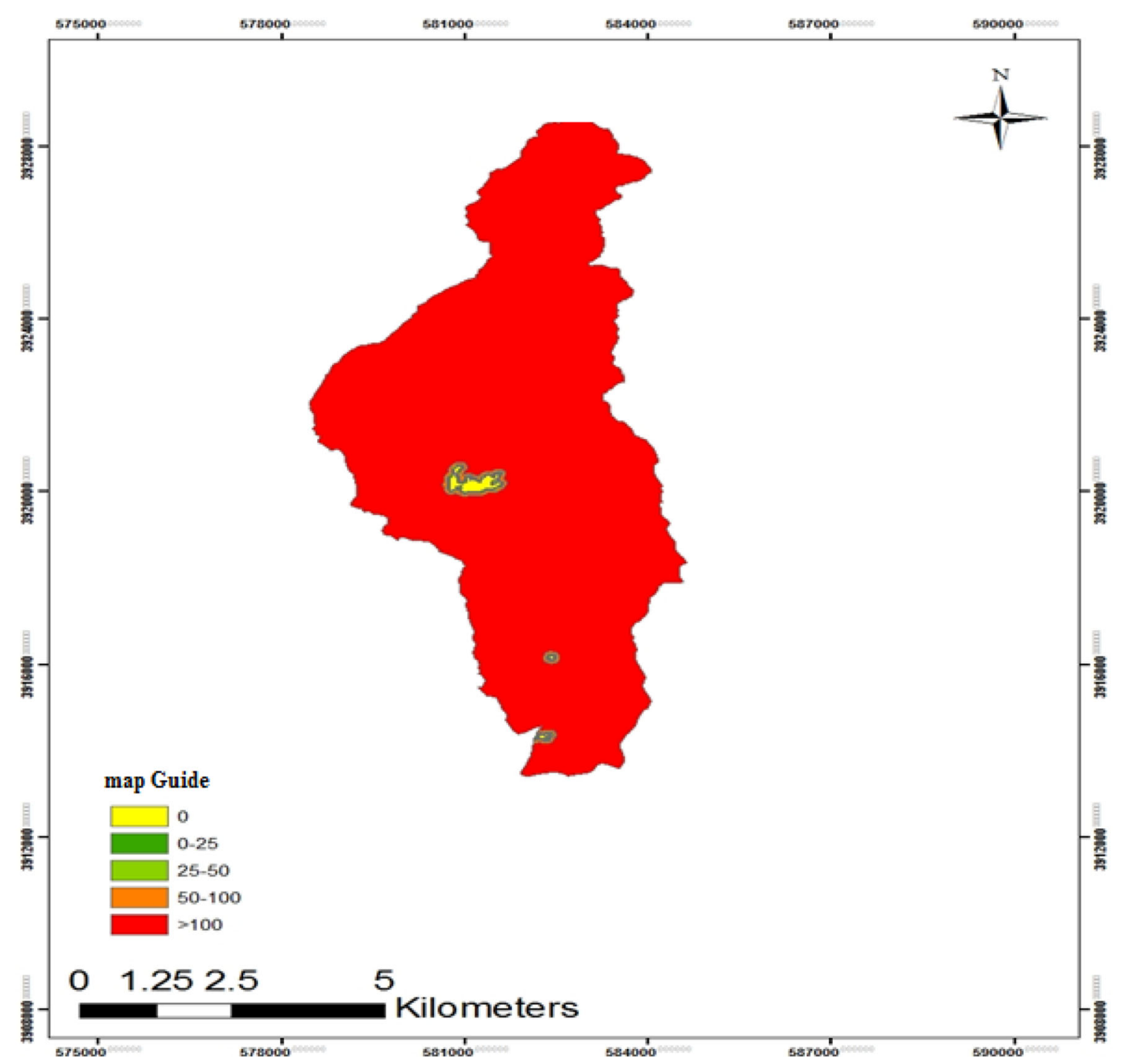

Fig. 6 The map of distance from residential area in the catchment "Kasef"

Monitoring the rate of incompatibility of decisionmakers' judgments is done based on mathematical relations using Expert Choice software. The values of incompatibility index (I.I) have been calculated for matrixes that their numbers were completely randomly chosen and named as incompatibility index of random matrix (I.I.R) so that their values for $\mathrm{n}$-dimensional matrixes are in accordance with Table 2.

For each matrix derived by dividing the incompatibility index (I.I) on inconsistency index of random matrix (I.I.R), will have the ratio of incompatibility (I.R) being as a good criterion to judge about the incompatibility of the matrixes (Relation 9). If the number is less than or equal to $0 / 1$, the compatibility of the system can be acceptable, otherwise the judgments should be revised (Qodsipoor 2006). Determining convenient locations of collecting runoff, maps achieved in Arc map software were finally combined together.

$I . R=\frac{I . I}{I . I . R}$

\section{Results}

Identifying potential areas of producing runoff is a critical step to localize suitable areas for using and applying runoff collecting systems. In this study, using capabilities of Geographical Information System (GIS) and Analytic Hierarchy Process (AHP), a proper and potential district was determined to apply these systems in the catchment "Kasef" that the results are presented in the following figures and tables (Figs. 3, 4, 5, 6, 7 and 8; Tables 3, 4, 5, 6 and 7). 


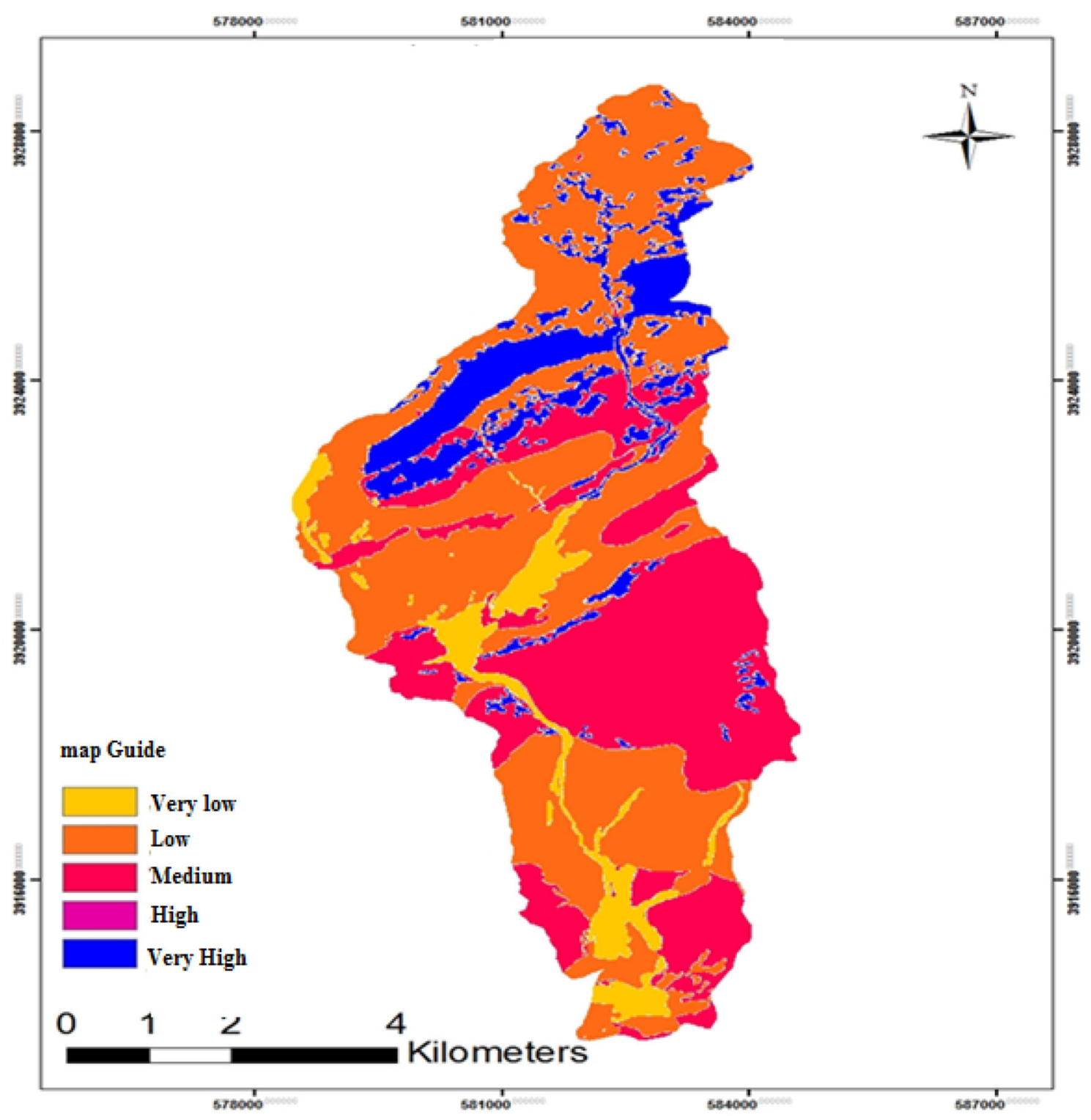

Fig. 7 The map of runoff potential in the catchment "Kasef"

\section{Discussion and conclusion}

Providing spatial information out of runoff producing areas is an important and essential step in implementing runoff collecting systems within the catchment. On the other hand, there has been required to local detailed reviews for spatial assessment of runoff that it would be difficult and costly for large areas. The method presented in this study introduces GIS as a powerful and useful tool for combining, storing, analyzing and managing spatial data which can be used at any scale of the catchment level as well as a logical method to help decision-making by identifying the catchment level, mapping and spatial evaluation. The output achieved in this method shows spatial display of runoff producing areas and suitable locations within the catchment. Thus, piloting runoff collecting systems to these areas, a significant amount of time and cost will be saved as well as increasing the efficiency of these systems. In this study, using Geographic Information Systems (GIS) and Analytic Hierarchy Process (AHP), there has been conducted the spatial evaluation of suitable areas for collecting runoff in the catchment "Kasef" and runoff potential criteria, distance from residential area and distance from arable land were also used as effective criteria in the process of decision-making. The results showed that according to expert opinions,. the criterion of runoff potential has allocated the utmost relative importance to assess susceptible areas for collecting runoff. Also, $2.35 \%$ and 114.68 hectares of the catchment area "Kasf" has a very high potential for runoff production and $12.27 \%$ and 


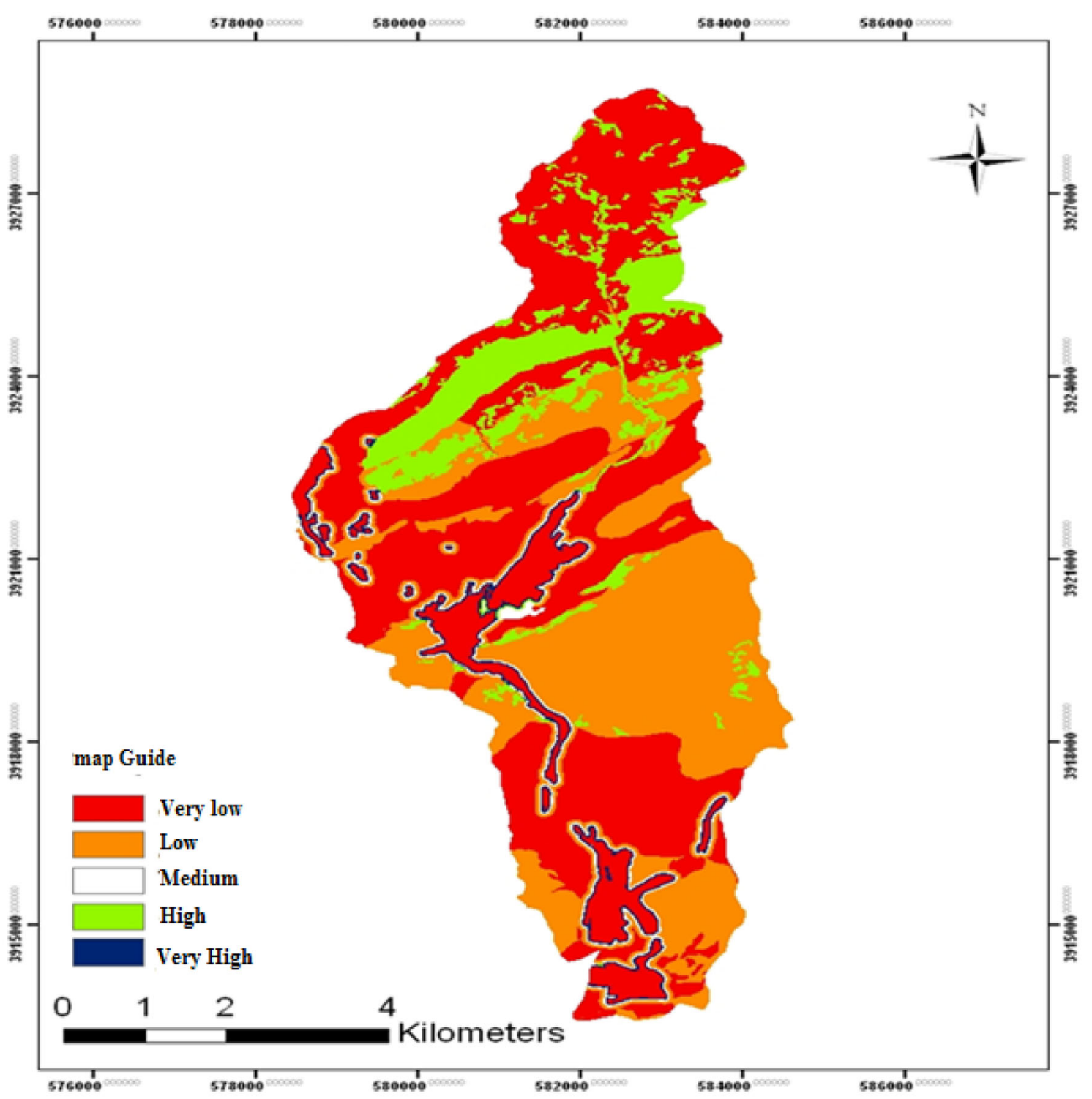

Fig. 8 The map of suitable locations for collecting runoff in the catchment "Kasef"

Table 3 The criteria of distant from the Distance from land and their relative importance

\begin{tabular}{llllllll}
\hline Class & 0 & $0-25 \mathrm{~m}$ & $25-50 \mathrm{~m}$ & $50-100 \mathrm{~m}$ & $100<\mathrm{m}$ & Geometric mean & Relative importance \\
\hline 0 & 1 & 3 & 8 & 8 & 9 & $4 / 4413$ & $0 / 5262$ \\
$0-25 \mathrm{~m}$ & $1 / 3$ & 1 & 7 & 7 & 8 & $2 / 6499$ & $0 / 3140$ \\
$25-50 \mathrm{~m}$ & $1 / 8$ & $1 / 7$ & 1 & 1 & 2 & $0 / 5135$ & $0 / 0608$ \\
$100-50 \mathrm{~m}$ & $1 / 8$ & $1 / 7$ & 1 & 1 & 2 & $0 / 5135$ & $0 / 0608$ \\
$100<\mathrm{m}$ & $1 / 9$ & $1 / 8$ & $1 / 2$ & $1 / 2$ & 1 & $0 / 3222$ & $0 / 0382$ \\
\hline
\end{tabular}

598.11 hectares of this catchment has a high potential and $48.66 \%$ and 2371.62 hectares has a very low potential. It was also noticed that $12.39 \%$ and 603.78 hectares of the catchment area "Kasef" has a very high proportion and $0.41 \%$ and 20.14 hectares has a high proportion and
$6.89 \%$ and 335.8 hectares has a very low proportion for the susceptible areas to collect runoff, which is consistent with the findings of Akbarpoor et al. (2008). We can finally say that spatial evaluation and identification of suitable areas to collect runoff is an important and necessary step in 
Table 4 The criteria of distant from the residential area and their relative importance
Table 5 Runoff potential criterion and their relative importance

\begin{tabular}{llllllll}
\hline Class & 0 & $0-25 \mathrm{~m}$ & $25-50 \mathrm{~m}$ & $50-100 \mathrm{~m}$ & $100<\mathrm{m}$ & Geometric mean & Relative importance \\
\hline 0 & 1 & 3 & 5 & 7 & 9 & $3 / 9363$ & $0 / 4914$ \\
$0-25 \mathrm{~m}$ & $1 / 3$ & 1 & 4 & 6 & 8 & $2 / 2974$ & $0 / 2868$ \\
$50-25 \mathrm{~m}$ & $1 / 5$ & $1 / 4$ & 1 & 5 & 7 & $1 / 1184$ & $0 / 1396$ \\
$100-50 \mathrm{~m}$ & $1 / 7$ & $1 / 6$ & $1 / 5$ & 1 & 3 & $0 / 4275$ & $0 / 0534$ \\
$100<\mathrm{m}$ & $1 / 9$ & $1 / 8$ & $1 / 7$ & $1 / 3$ & 1 & $0 / 2313$ & $0 / 0289$ \\
\hline
\end{tabular}

\begin{tabular}{llllllll}
\hline Class & Very high & High & Medium & Low & Very low & Geometric mean & Relative importance \\
\hline Too many & 1 & 5 & 7 & 8 & 9 & $4 / 7894$ & $0 / 5498$ \\
Many & $1 / 5$ & 1 & 5 & 7 & 8 & $2 / 2369$ & $0 / 2568$ \\
Medium & $1 / 7$ & $1 / 5$ & 1 & 6 & 7 & $1 / 0371$ & $0 / 1190$ \\
Few & $1 / 8$ & $1 / 7$ & $1 / 6$ & 1 & 6 & $0 / 4471$ & $0 / 0513$ \\
Very few & $1 / 9$ & $1 / 8$ & $1 / 7$ & $1 / 6$ & 1 & $0 / 2013$ & $0 / 0231$ \\
\hline
\end{tabular}

Table 6 The main criteria and their relative importance

\begin{tabular}{lllll}
\hline Classes & $\begin{array}{l}\text { Runoff } \\
\text { potential }\end{array}$ & $\begin{array}{l}\text { Distance from arable } \\
\text { land }\end{array}$ & $\begin{array}{l}\text { Distant from residential } \\
\text { area }\end{array}$ & $\begin{array}{l}\text { Geometric } \\
\text { mean } \\
\text { importance }\end{array}$ \\
\hline Runoff potential & 1 & 5 & 9 & $3 / 5569$ \\
$\begin{array}{l}\text { Distance from arable land } \\
\text { Distant from residential }\end{array}$ & $1 / 5$ & 1 & 5 & 1 \\
$\quad 1 / 9$ & $1 / 5$ & 1 & $0 / 7352$ & $0 / 2811$ \\
\hline area & & & & 0581 \\
\hline
\end{tabular}

Table 7 The proportion, level and percentage of the areas having the potential to produce and collect runoff

\begin{tabular}{llllll}
\hline Proportion & \multicolumn{2}{l}{ The potential of producing runoff } & & \multicolumn{2}{l}{ The potential of collecting runoff } \\
\cline { 2 - 3 } \cline { 5 - 6 } \cline { 5 - 6 } & Percent of the area & The area in hectares & & The percentage of area & The area in hectares \\
\hline Very high & $2 / 35$ & $114 / 68$ & $12 / 39$ & $603 / 78$ \\
High & $12 / 27$ & $598 / 11$ & $0 / 41$ & $20 / 14$ \\
Medium & $2 / 15$ & $105 / 18$ & $32 / 52$ & 1585 \\
Low & $34 / 55$ & $1683 / 92$ & $47 / 79$ & 2329 \\
Very low & $48 / 66$ & $2371 / 62$ & $6 / 89$ & $335 / 8$ \\
\hline
\end{tabular}

applying and developing runoff collecting systems in each system of catchments.

\section{References}

Akbarpoor A, Khashei siuki A, Keshavarz A, Phoroghi far H (2008) Determining suitable locations of collecting rain water to use in agricultural consumptions using AHP model (case study: the catchment of Birjand). J Catchment Manag 6(12):65-74

Asgharpoor MJ (2015) "Multi-Criteria Decision Making", publication of Tehran University, the Institute of the printed publication, p 400

Biazin B, Sterk G, Temesgen M, Abdulkedir A, Stroosnijder Leo (2011) Rainwater harvesting and management in rainfed agricultural systems in sub-Saharan Africa-a review. Phys Chem Earth, p 13 de Winnaar G, Jewitt GPW, Horan M (2007) A GIS-based approach for identifying potential runoff harvesting sites in the Thukela River basin, South Africa. Phys Chem Earth 32:1058-1067

DeBarry PA (2004) Watersheds: processes, assessment, and management. Wiley, USA

Durga Rao KHV, Hariprasad V, Roy PS (2005) A suitable site. In: Khurana I (ed) Making water everybody's business. Centre for Science and Environment, New Delhi, pp 243-245

Kheirkhah Zarkesh M (2005) DSS for floodwater site selection in Iran, Ph.D. Thesis, Wageningen University, pp 273

Kordavani P (2004) "Water resources and issues in Iran", volume 1, surface and groundwater and issues and exploiting them", VII publication, Tehran University, p 414

Mbilinyi BP, Tumbo SD, Mahoo HF, Senkondo EM, Hatibu N (2001) Indigenous knowledge as decision support tool in rainwater harvesting. Phys Chem Earth 30:792-798

Nasarian S, Najafi nejad A, Noura N (2015) "Spatial evaluation of superficial water collecting potential in the catchment "Agh Emam" in Golestan". J Water Soil 29(1):1-11 
Neitsch S, Arnold J, Kiniry J, Williams J (2005) Soil and water assessment tool-theoretical documentation, version 2005. Blackland Research Center, Temple, TX, USA

Prakash TN (2003) Land suitability analysis for agricultural crops: a fuzzy multicriteria decision making approach, M.Sc Thesis International Institute for Geo-information Science and Earth Observation, Enschede, The Netherlands, pp 68

Qodsipoor H (2006) "Topics in multi-criteria decision making", Amirkabir Technical University Press, (Tehran Polytechnic), p 220
Rockstro MJ (2000) Water resources management in smallholder farms in Eastern and Southern Africa: an overview. Phys Chem Earth 25(3):275-283

Sutherland DC, Fenn CR (2000) Assessment of water supply options. Prepared for the World Commission on Dams, Cape Town, 8018, South Africa, p 143

Vorhauer CF, Hamlett JM (1996) GIS: a tool for sitting farm ponds. J Soil Water Conservation 51(5):434-438 